\title{
MA Defence: “Creativity Within Constraints: Encoding, Production, and Representation in Battlestar Galactica" by Philippa Adams
}

\section{Vu Thuy Anh Phan}

School of Communication

Simon Fraser University

Our dear colleague, Philippa Adams, will defend her MA Thesis on Friday, December 10th, 2015 at Harbour Centre, Room 1520 (2:00 pm - 4:00 pm). Here is the abstract of her thesis "Creativity Within Constraints":

\begin{abstract}
Through the lens of feminist production studies, I examine the television show Battlestar Galactica through interviews with show creators to explore the contexts of production. Writers, actors, and productions experience constraints on their creativity. Media producers encode meaning into the texts they create and form their own understandings of social issues and stories. I examine the day-to-day processes and constraints operating in the work lives of television creators as well as their political and social goals for the show. I pay particularly close attention to their understanding of intersecting areas of identity, such as race, sexuality, and gender. My analysis is situated within production studies, postfeminist media theories, and science fiction scholarship.
\end{abstract}

Keywords: media encoding; production studies; science fiction television, Battlestar Galactica; postfeminism 